\title{
EQUISETIN, REUTERICYCLIN AND STREPTOLODYGIN AS NATURAL PRODUCT LEAD STRUCTURES FOR NOVEL ANTIBIOTIC LIBRARIES
}

\author{
Yong-Chul Jeong and Mark G. Moloney* \\ Chemistry Research Laboratory, University of Oxford, Mansfield Rd, University of Oxford, \\ OX1 3TA, U.K.
}

Tel: +44 1865 275656; e-mail: mark.moloney@chem.ox.ac.uk

\begin{abstract}
The emergence of antimicrobial resistance has created a need for the development of novel antibacterial therapies to treat infection. Natural products which exhibit antibacterial activity offer validated starting points for library generation, and we report here that small molecule mimics of tetramate-containing natural products may show antibacterial activity and offer the potential for further optimisation.
\end{abstract}

\section{Introduction}

There has been a realisation that the antibacterial drug pipeline has begun to run dry [1-3] and that commercially-driven models for drug development within the pharmaceutical industry which have been hitherto highly successful are unlikely to serve so well for new antibacterial drug development in the twenty-first century.[4-8] This, coupled with the emergence of antibacterial resistance,[9-11] has begun to compromise modern medical practice, and a number of government reports have highlighted the urgency, but also the scientific, technological, commercial and societal challenges, of responding to this threat.[4, 12-14] Faced with this need for action, there has been discussion of the most appropriate methodological approach to be deployed[15-21] especially in a resource-limited environment. It has also been recognised that, unlike many other therapeutic areas, there are challenges peculiar to antibacterial drug discovery[22-27] which mitigate against success. Historically, natural products have provided a very important start point in antibacterial therapies and drug discovery[15, 28-34] and of interest is that antibacterially active natural products appear to occupy an unusual chemical property space,[22, 35, 36] offering excellent opportunity for exploitation for drug development.[37] We have become interested in tetramate-containing natural products,[38, 39] many of which have been known for some time, including for example equisetin[40], reutericyclin[41] and streptolodygin[42], but which still continue to be discovered, e.g. kibdelomycin (Figure 1).[43] These exhibit a range of biological activities, importantly including antibacterial properties, for which some, e.g. reutericyclin, vermisporin, equisetin, BU4514N, delaminomycin C, PF1052, oxasetin, and vancoresmycin (Figure 2), are quite active. Inspired by this precedent, small molecule mimics 1-3 of such systems have been reported, and of interest is that these too show antibacterial activity (Figure 3).[44-47] In a statistical analysis, we have shown that, in general, (a) Gram-negative antibacterial agents tend to be more charged than the Grampositive only agents, presumably to facilitate penetration of the outer membrane via porins as well as prevent efflux, (b) most antibiotics, with the exception of topical agents, tend to 
have a higher limit for lipophilicity (ClogD7.4 $<2.0$ and ClogP $<3.0$ ) and a lower limit for polar surface area (PSA $>60 \AA^{2}$ and rel-PSA $>13 \%$ ); and (c) Gram-negative antibacterial agents tend to be more charged than the Gram-positive only agents, presumably to penetrate the outer membrane via porins as well-as prevent efflux. [48]. Against this backdrop, it was of interest to examine small highly acidic tetramate systems, with the aim to introduce several points of diversity into the synthesis (Figure 4) and we report details of this work here.

\section{Discussion}

Our first requirement was to establish direct but versatile protocols for tetramate synthesis, and this was done by optimisation of literature approaches;[49] elaboration of a suitably protected glycine with either mono-ethylmalonate or Meldrum's acid gave the corresponding tetramates 4-6 in a short high-yielding sequence. Significantly, however, in order to achieve closer mimics to the natural products, we needed to be able to $C$-acylate the tetramate core to give derivatives $\mathbf{7 , 8}$, and this was most effectively achieved using either acetone cyanohydrin or an $\mathrm{O}$-acylation-rearrangement sequence which we recently reported (Scheme-Figure 51).[50, 51] The latter approach proved to be very general, enabling the ready introduction of a wide variety of aromatic, heteroaromatic, and alkyl carbonyl side chains, and provided access to a library of monocyclic tetramate derivatives (the TA, HTA, CTA, PTA, RTA and BTA series), with variation of substitution at $2 \underline{3}$ points around the heterocyclic ring (Figure 65 ). [52-55] These libraries were readily structurally characterised using NMR and MS techniques. Of interest is that complex keto-enol behaviour was frequently observed in these compounds, in which different species preponderated, principally depending on the nature of the side chain and the identity of the $\mathrm{N}$-substituent. All Thus, $\mathrm{N}$-H and $\mathrm{N}$-alkyl forms favour exo-enol form $\underline{\mathrm{C}} \mathrm{D}$, but $\mathrm{N}$-acyl 3-acyltetramates favour forms $A B$ and $C D$ approximately equally, although for those with $\beta$-heteroatom functionality on the 3-acyl unit, pair $A B$ becomes even more preferred, and is sometimes exclusively formed-(Figure 76). In order to extend the series, the 3-carboxethoxy and 3-carboxamido series (ETA and ATA series) were also prepared.[52,55] To our surprise, initial antibacterial assay by hole-plate analysis against $S$. aureus and $E$. coli showed activity for a substantial subset of the library, although of interest was that $O$-acyl derivatives were universally inactive (Table 1). This activity was dose dependent, and in one case superior to the Cephalosporin C control (Figure $\underline{8} 7$ ). This outcome compared favourably with structurally similar compounds reported previously.[45, 46]

Table 1: Antibacterial activity of selected compounds from Figure $\underline{6} 5$.

\begin{tabular}{|c|c|c|c|c|}
\hline \multirow{3}{*}{ Entry } & \multirow{3}{*}{ Compounds } & \multicolumn{3}{|c|}{ Minimum inhibition concentration $(\mu \mathrm{g} / \mathrm{ml})^{\mathrm{a}}$} \\
\cline { 3 - 5 } & & $\begin{array}{c}\text { Staphylococcus aureus } \\
\text { D267 }\end{array}$ & \multicolumn{2}{|c|}{ Escherichia coli X580 } \\
\cline { 3 - 5 } & & & Neutral pH & $\mathrm{pH} 4.5$ buffer \\
\hline 1 & TA-PH & $>4000$ & 4000 & 800 \\
\hline
\end{tabular}




\begin{tabular}{|c|c|c|c|c|}
\hline 2 & TA-NA & 2000 & 2000 & 1000 \\
\hline 3 & TA-CY & 800 & 800 & 400 \\
\hline 4 & TA-C6 & 400 & 200 & 20 \\
\hline 5 & TA-OPH & $>4000$ & 800 & - \\
\hline 6 & TA-ONA & $>4000$ & 400 & - \\
\hline 7 & TA-OCY & $>4000$ & 800 & - \\
\hline 8 & TA-OC6 & $>4000$ & 800 & - \\
\hline 9 & Cephalosporin Cc & 200 & 2 & \\
\hline
\end{tabular}

a: Determined by disc diffusion method [57]; b; Cephalosporin C was used as the standard

Follow up analysis by Minimum Inhibitory Concentration (MIC) evaluation against a panel of Gram positive and negative bacteria (Gram-positive bacteria including Staphylococcus aureus (methicillin sensitive, vancomycin susceptible, non-resistant and methicillin-resistant in vivo, MRSA), Enterococcus faecalis (vancomycin susceptible, VSE), E. faecium (vancomycin resistant, VRE) and S. pneumonia (erythromycin susceptible and multi drug resistant, MDRSP) as well as Gram-negative bacteria including Pseudomonas aeruginosa, Escherichia coli (efflux-positive Ec50 and -negative Ec49) and Haemophilus influenzae (efflux-positive and -negative) using broth assay verified these initial assessments, and showed strong activity against Gram positive but lower efficacy against Gram negative bacteria.[48, 52-55] Cheminformatic analysis with comparing a range of parameters and comparison to bioactivity was instructive; of interest was to investigate the role of hydrophobicity, steric and electronic effects using the descriptors MSA, PSA, \%PSA and clogP. Thus, it was evident that the most active Gram positives clustered around ClogP and MSA values of $4 \pm 0.5$ and $670 \pm 30$, respectively, while the most active Gram negatives had narrower ClogP and MSA values around $2.5 \pm 0.5$ and $530 \pm 50$, respectively (Figure $98 A, B, D, E)$. This difference in behaviour was reflected in rel PSA (PSA/MSA $\times 100)$ values for each of the most active Gram positive and Gram negative systems, with values of $12 \pm$ $2 \%$ and $14 \pm 1 \%$, respectively (Figure $98 \mathrm{C}, \mathrm{F}$ ). When grouped by chemical structure, the most active against $S$. aureus ATCC 25923 were the RTA and CTA systems, interestingly with similar preference for ClogP ( $\approx 3.5)$, MSA (650), PSA (78) and rel-PSA (12\%) (Figure 109). The most active compounds (RTA-C3, RTA-C5, CTA-NR, TA-C11, CTA-C6 and CTAC9) occupied a narrow region of property space defined by ClogP, MSA and rel-PSA (Figure $1 \underline{10}$ and Table 2).

Table 2: Active compounds and their cheminformatic descriptors. 


\begin{tabular}{|l|l|l|l|l|}
\hline Compounds & $\begin{array}{l}\text { MIC }(\mu \mathrm{g} / \mathrm{ml}, \\
\text { S. aureus) }\end{array}$ & ClogP & MSA & rel PSA \\
\hline Most active: CTA-C9, RTA-C3 \& RTA-C5 & $0.125-0.5$ & $3.6-4.47$ & $631-693$ & $11.2-12.3$ \\
\hline Active: TA-C11, CTA-NR \& CTA-C6 & $0.5-2$ & $2.19-2.98$ & $483-545$ & $14.2-14.3$ \\
& & & & \\
\hline
\end{tabular}

Selectivity between organisms was examined for each of the main compound classes (Figure 121). Noteworthy is that for the Gram positive organisms, SA25923 and SA13709, the identity of the $\mathrm{N}$-substituent was very important, with $\mathrm{N}$-acyl being much more active than $\mathrm{N}-\mathrm{H}_{2}$ which in turn was more active than $\mathrm{N}$-alkyl and shorter chain $\mathrm{N}$-acyl (Figure 121 $1 \mathrm{~A}-\mathrm{C}$ ). However, this pattern altered for E. faecalis, E. faecium, and S. pneumonia (Figure 121D-F) L, although the $\mathrm{N}-\mathrm{H}$ system was universally at the lower end of activity. This offers the possibility of the design of species-specific antibacterial tetramate systems. SAR may be summarised as in Figure $12 \underline{13}$, in which the C-acyl substituent has a positive effect on antibacterial activity for longer chain length, and enhanced activity is seen in cases with an $\mathrm{N}$-acyl substituent over $\mathrm{N}$-alkyl or $\mathrm{N}-\mathrm{H}$, or a C-2 alkyl substituent. $\alpha, \beta$-Unsaturated $\mathrm{N}$-acyl groups are preferred, while shorter chain lengths at this position are less effective (Figure 132). Of interest is that the headline MIC values for representative systems compare favourably in activity with other lead structures of interest in antibacterial drug discovery (Figure 1노).

Extension of this approach from five membered to six membered rings as also examined, since similar behaviour might have been expected (Scheme 2Figure 15). These systems 9$\mathbf{1 1}$ were readily accessed by analogous chemistry, and of interest is that many showed high levels of activity.[48]

It might be argued that this approach has merely identified systems by chance, but related small polar molecules, not possessing the highly enolised tetramate core, do not show activity. Thus, 1,5,5-trimethylimidazolidine-2,4-dione systems were examined with a range of $N$-substitution (Figure 1 $1 \underline{6} 4$ ); these systems are arguably structurally similar to the tetramates, but do not possess the highly enolisable tetramate core, and were found to possess only very low activity. This outcome is consistent with the fact that the enolisable tetramate system is necessary but not sufficient for bioactivity. On the other hand, not all systems modelled on natural products show antibacterial activity: pyroglutaminols $\mathbf{1 1}$ and $\mathbf{1 2}$ modelled on pramanicin 13 were devoid of activity, with the exception of the phenylacetylenyl epoxidesystem, which was weakly active against S. aureus (Figure 17).[56]

This phenotypic approach using natural product lead structures to inform library design contrasts with a target-based approach, but nonetheless has led to the identification of novel templates suitable for elaboration to antibacterially active compound libraries. A key benefit of this approach is that bacterial cell wall permeability is automatically built in to active library 
members, and does not need retro-fitting as would be required in a target driven approach. Further investigation has shown that tetramates may exhibit RNA polymerise, undecaprenyl pyrophosphate synthase, topoisomerase or gyrase inhibitory activity, and that some exhibit dual modes of action, although for others no mode of action has yet been identified. It is hoped that future work will permit optimisation against these targets, will enhance biological activity, and provide the identification of suitable lead candidates.

\section{Conclusion}

We have shown that antibacterially active natural products provide a useful start point for the identification of novel new chemical entities, suitable for investigation as antibacterial agents, and that modified tetramates in particular offer unusual systems with potential for further exploitation in antibacterial drug development.

\section{Acknowledgements}

We are particularly grateful for valuable input by Phil Dudfield, John Lowther, and for funding by Galapagos SASU (France).

\section{References}

1. Boucher HW, Talbot GH, Benjamin DK et al.: $10 \times$ '20 Progress-Development of New Drugs Active Against Gram-Negative Bacilli: An Update From the Infectious Diseases Society of America. Clin. Infect. Dis. 56, 1685-1694 (2013).

**2. Butler MS, Cooper MA: Antibiotics in the Clinical Pipeline in 2011. J. Antibiot. 64, 413-425 (2011). (A thorough review of the current status of clinical candidates)

3. Saleem M, Nazir M, Ali MS et al.: Antimicrobial natural products: an update on future antibiotic drug candidates. Nat. Prod. Rep. 27, 238-254 (2010).

4. Kinch MS, Patridge E, Plummer M, Hoyer D: An analysis of FDA-approved drugs for infectious disease: antibacterial agents. Drug Discovery Today 19(9), 1283-1287 (2014).

5. Kraus CN: Low hanging fruit in infectious disease drug development. Current Opinion in Microbiology 11, 434-438 (2008).

6. Christoffersen RE: Antibiotics - an investment worth making? Nature Biotech 24, 1512-1514 (2006).

7. Fox JL: The business of developing antibacterials. Nat Biotech 24, 1521-1528 (2006).

8. Katz ML, Mueller LV, Polyakov M, Weinstock SF: Where have all the antibiotic patents gone? Nat Biotech 24, 1529-1531 (2006).

9. Anderson AC, Pollastri MP, Schiffer CA, Peet NP: The challenge of developing robust drugs to overcome resistance. Drug Discovery Today 16, 755-761 (2011).

10. Hurdle JG, O'Nneill AJ, Chopra I, Lee RE: Targeting bacterial membrane function: an underexploited mechanism for treating persistent infections. Nat. Rev. Microbiol. 9, 62-75 (2011).

11. Wright GD: Molecular mechanisms of antibiotic resistance. Chem. Commun. 47, 4055-4061 (2011).

12. UK Five Year Antimicrobial Resistance Strategy 2013-2018. (2013).

13. Spellberg B, Guidos R, Gilbert D et al.: The Epidemic of Antibiotic-Resistant Infections: A Call to Action for the Medical Community from the Infectious Diseases Society of America. Clinical Infectious Diseases 46, 155-164 (2008).

14. O'Nneill, J: Antimicrobial Resistance:Tackling a crisis for the health and wealth of nations. Antimicrobial Resistance:Tackling a crisis for the health and wealth of nations, (2014). 
15. Brown DG, Lister T, May-Dracka TL: natural products as leads for antibacterial drug discovery. Biorg. Med. Chem. Lett. 24, 413-418 (2014).

16. Walsh CT, Wencewicz TA: Prospects for new antibiotics: a molecule-centered perspective. J. Antibiot. 67, 7-22 (2014).

17. Butera JA: Phenotypic Screening as a Strategic Component of Drug Discovery Programs Targeting Novel Antiparasitic and Antimycobacterial Agents. J. Med. Chem. 56, 7715-7718 (2013).

18. Zheng W, Thorne N, Mckew JC: Phenotypic screens as a renewed approach for drug discovery. Drug Discov Today 18, 1067-1073 (2013).

19. Newman DJ, Cragg GM: Natural Products As Sources of New Drugs over the 30 Years from 1981 to 2010. J. Nat. Prod. 75, 311-335 (2012).

20. Hughes J, Rees S, Kalindjian S, Philpott K: Principles of early drug discovery. British Journal of Pharmacology 162, 1239-1249 (2011).

21. Swinney DC, Anthony J: How were new medicines discovered? Nat. Rev. Drug Discovery 10, 507-519 (2011).

$* * 22$. Singh SB: Confronting the challenges of discovery of novel antibacterial agents. Biorg. Med. Chem. Lett. 24, 3683-3689 (2014). (An excellent overview of challenges in antibacterial drug discovery)

$\overline{23}$ Silver LL: Challenges of Antibacterial Discovery. Clin. Microbiol. Rev. 24, 71-109 (2011). (An excellent overview of challenges in antibacterial drug discovery)

24. Dick T, Young D: How antibacterials really work: impact on drug discovery. Future Microbiol. 6, 603-604 (2011).

25. Gwynn MN, Portnoy A, Rittenhouse SF, Payne DJ: Challenges of antibacterial discovery revisited. Ann. N.Y. Acad. Sci. 1213, 5-19 (2010).

26. Williams KJ, Bax RP: Challenges in developing new Antibacterial Drugs. Current Opinion in Investigational Drugs 10, 157-163 (2009).

**27. Payne DJ, Gwynn MN, Holmes DJ, Pompliano DL: Drugs for bad bugs: confronting the challenges of antibacterial discovery. Nat. Rev. Drug Discovery 6, 29-40 (2007). (An excellent overview of recent experience within pharma of lessons learnt in antibacterial drug discovery)

28. Bumann D: Has nature already identified all useful antibacterial targets? Curr. Opin Microbiol. 11(5), 387-392 (2008).

29. Silver LL: Are natural products still the best source for antibacterial discovery? The bacterial entry factor. Expert Opinion on Drug Discovery 3(5), 487-500 (2008).

30. Vonnussbaum F, Brands M, Hinzen B, Weigand S, D. Habich: Antibacterial Natural Products in Medicinal Chemistry-Exodus or Revival? Angew. Chem. Int. Ed. 45, 5072-5129 (2006).

31. Clardy J, Fischbach MA, Walsh CT: New antibiotics from bacterial natural products. Nat Biotech 24, 1541-1550 (2006).

32. Butler MS, Buss AD: Natural products - The future scaffolds for novel antibiotics? Biochemical Pharmacology 71(7), 919-929 (2006).

33. Gullo VP, Mcalpine J, Lam KS, Baker D, Petersen F: Drug discovery from natural products J. Ind. Microbiol. Biotechnol. 33, 523-531 (2006).

34. Butler MS: The Role of Natural Product Chemistry in Drug Discovery. J. Nat. Prod. 67, 21412153 (2004).

35. O'shea R, Moser HE: Physicochemical Properties of Antibacterial Compounds: Implications for Drug Discovery. J. Med. Chem. 51, 2871-2878 (2008).

36. O’Naneill AJ, Chopra I: Expert Opin. Drug Discov. 13, 1045-1063 (2004).

37. Quinn RJ, Carroll AR, Pham NB et al.: Developing a Drug-like Natural Product Library. J. Nat. Prod. 71, 464-446 (2008). 
*38. Royles BJL: Naturally-Occurring Tetramic Acids - Structure, Isolation, And Synthesis. Chem. Rev. 95, 1981-2001 (1995). (Review of tetramate natural products)

39. Schobert R, Schlenk A: Tetramic and tetronic acids: An update on new derivatives and biological aspects. Bioorg. Med. Chem. 16, 4203-4221 (2008).

40. Singh SB, Zink DL, Goetz MA, Dombrowski AW, Polishook JD, Hazuda DJ: Equisetin and a novel opposite stereochemical homolog phomasetin, two fungal metabolites as inhibitors of HIV-1 integrase. Tetrahedron Lett. 39, 2243-2246 (1998).

41. Jung G, Hammes W, Ganzle M, Marquardt U, Holtzel A: Reutericyclin. EP 1 116 715(EP 1116 715), EP 1116715 (2000).

42. Tuske S, Sarafianos SG, Wang X et al.: Inhibition of Bacterial RNA Polymerase by Streptolydigin: Stabilization of a Straight-Bridge-Helix Active-Center Conformation. Cell 122, 541-552 (2005).

43. Phillips J, Goetz M, Smith S et al.: Discovery of Kibdelomycin, A Potent New Class of Bacterial Type II Topoisomerase Inhibitor by Chemical-Genetic Profiling in Staphylococcus aureus. Chem Biol. 18, 955-965 (2011).

44. Rosen T, Fernandes PB, Marovich MA, Shen L, Mao J, Pernet AG: Aromatic Dienoyl Tetramic Acids. Novel Antibacterial Agents with Activity against Anaerobes and Staphylococci. J. Med. Chem. 32, 1062-1069 (1989).

45. Matsuo K, Kimura M, Kinuta T, Takai N, Tanaka K: Synthesis and Antimicrobial Activities of 3Acyltetramic Acid Derivatives. Chem. Pharm. Bull. 32, 4197-4204

46. Matsuo K, Kitaguchi I, Takata Y, Tanaka K: Chem. Pharm. Bull. 28, 2494-2502 (1980).

47. Yendapally R, Hurdle JG, Carson El, Lee RB, Lee RE: N-Substituted 3-Acetyltetramic Acid Derivatives as Antibacterial Agents. J. Med. Chem. 51, 1487-1491 (2008).

48. Jeong Y-C, Moloney MG: Antibacterial barbituric acid analogues inspired from natural 3acyltetramic acids; Synthesis, tautomerism and structure and physicochemical propertyantibacterial activity relationships. Molecules 20, 3582-3627 (2015).

49. Jeong Y-C, Moloney MG: Tetramic acids as bioactive templates: synthesis, tautomeric and antibacterial behaviour. Synlett., 2487-2491 (2009).

50. Jeong Y-C, Moloney MG: Synthesis of and Tautomerism in 3-Acyltetramic Acids. J. Org Chem. 76, 1342-1354 (2011).

51. Schlenk A, Diestel R, Sasse F, Schobert R: Chem. Eur. J. 16, 2599-2604 (2010).

52. Jeong Y-C, Moloney MG, Bikadi Z, Hazai E: A Detailed Study of Antibacterial 3-Acyltetramic Acids and 3-Acylpiperidine-2,4-diones. ChemMedChem 9, 1826-1837 (2014).

53. Jeong Y-C, Anwar M, Moloney MG, Bikadi Z, Hazai E: Synthesis, antibiotic activity and structure-activity relationship study of some 3-enaminetetramic acids. Biorg. Med. Chem. Lett. 24, 1901-1906 (2014).

54. Jeong Y-C, Moloney MG: Synthesis and antibacterial activity of monocyclic 3carboxamidotetramic acids. Beilstein J. Org. Chem. 9, 1899-1906 (2013).

55. Jeong Y-C, Anwar M, Moloney MG, Bikadi Z, Hazai E: Natural product inspired antibacterial tetramic acid libraries with dual enzyme target activity. Chem. Sci. 4, 1008-1015 (2013).

56. Tan BSW, Chai CLL, Moloney MG, Thompson AL: Synthesis of Mimics of Pramanicin from Pyroglutamic Acid and Their Antibacterial Activity. J. Org. Chem. 80, 2661-2675 (2015).

57. Smith B, Warren SC, Newton GGF and Abraham EP, 890Biosynthesis Of Penicillin N And Cephalosporin C - Antibiotic Production And Other Features Of Metabolism Of A Cephalosporium Species, Biochem. J., 1967, 103, 877- 
antibacterial resistance: the loss of susceptibility of bacteria to the lethal effects of antibacterial agents.

Cheminformatic analysis: the use of computational analysis to characterise and uncover trends in the structures of molecules, and their bioactivity

phenotypic approach: drug design based upon the development of molecules with whole cell or whole organism effects

target-based approach: drug design based upon the development of molecules which act against a known molecular (often an enzyme) target.

lipophilicity: the solubility of a compound in non-polar solvents such as hexane or toluene, fats, oils and lipids.

Future perspective: The development of effective antibacterial therapies over the last century must surely rank as one of the major achievements of humankind, and modern medical practice assumes their ready availability. Over the last decade in particular, however, the emergence of resistant and virulent bacterial strains has come to threaten the viability of such treatment, and therefore even of modern society itself. There is now an urgent need to identify and develop new strategies for finding new therapies, along with new therapies themselves, but society would now seem to be badly underprepared for this challenge. We have attempted to show in our work that a return to natural product chemistry - which has been a crucial element in antibacterial development over the last century, but more recently been forgotten - offers interesting and worthwhile opportunities. Tetramate systems in particular seem worthy of more detailed examination, although whether they prove to be a new "magic bullet" will remain to be seen.

\section{Executive Summary:}

- $\quad$ The emergence of antimicrobial resistance has created a need for the development of novel antibacterial therapies to treat infection.

- $\quad$ Natural products which exhibit antibacterial activity offer validated starting points for library generation

- $\quad$ Small molecule mimics of tetramate-containing natural products may be readily prepared with a wide range of chemical diversity.

- $\quad$ Tetramate libraries show high levels of antibacterial activity against a panel of Gram positive and Gram-negative bacteria.

- $\quad$ This strategy is sufficiently general that there is significant potential for further optimisation.
Formatted: Font: +Body (Calibri)

Formatted: Font: +Body (Calibri)

Formatted: Font: +Body (Calibri)

Formatted: Font: +Body (Calibri)

Formatted: Font: +Body (Calibri) 

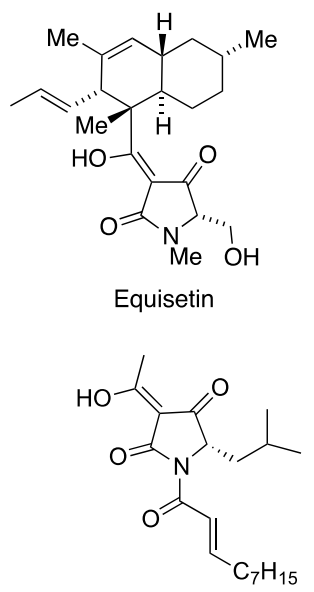

Reutericyclin

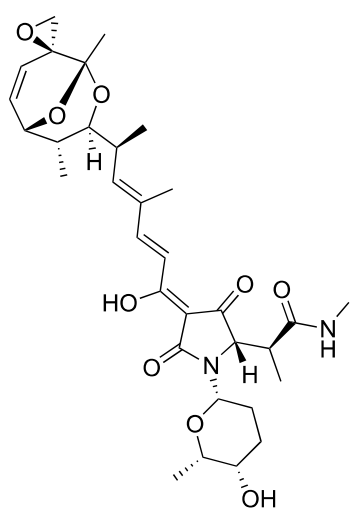

Streptolydigin

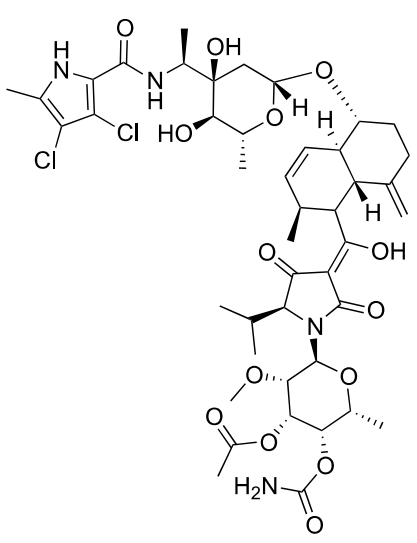

Kibdelolomycin

Figure 1

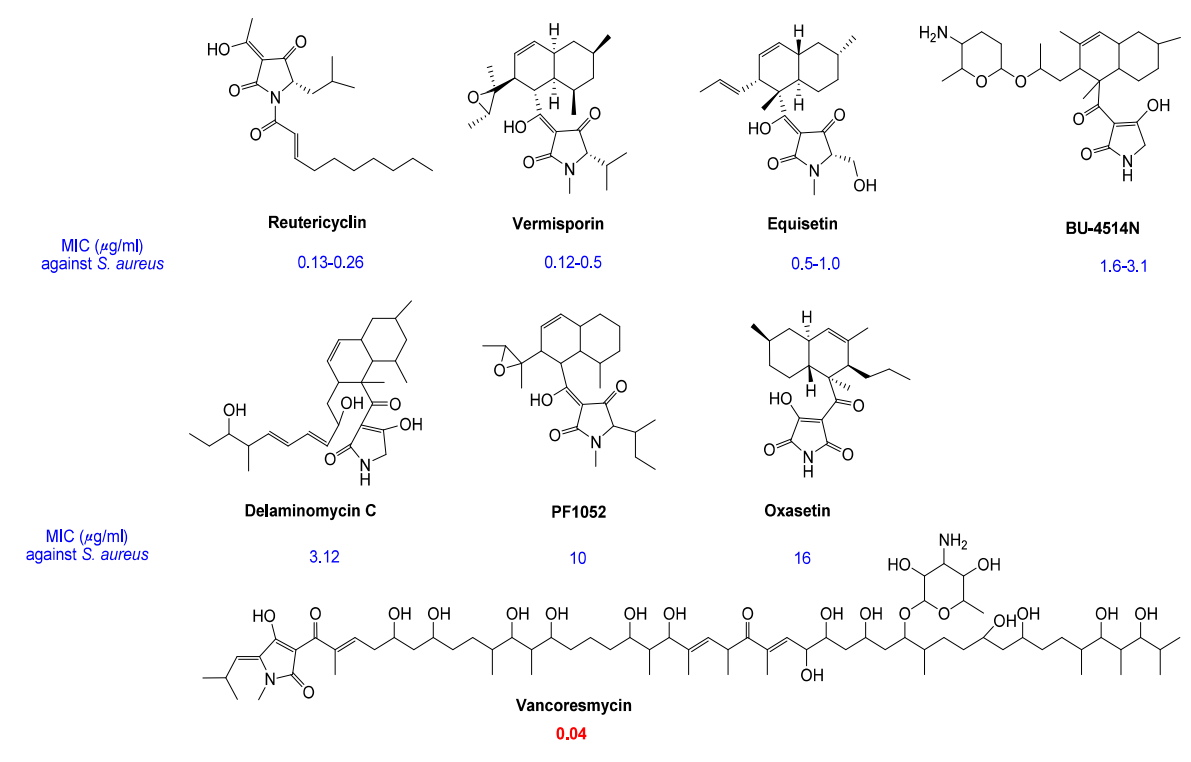

Figure 2 


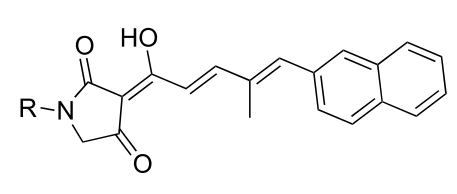

$$
1 \mathrm{R}=\mathrm{H}, \mathrm{CH}_{3}
$$

MIC $(\mu \mathrm{g} / \mathrm{ml})$ against $S$. 0.78-1.56

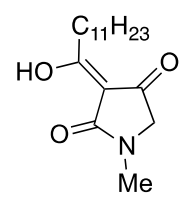

2

1.56

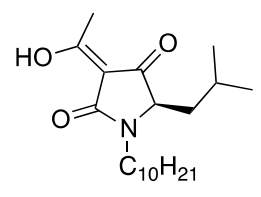

3

$0.4-0.8$

Figure 3
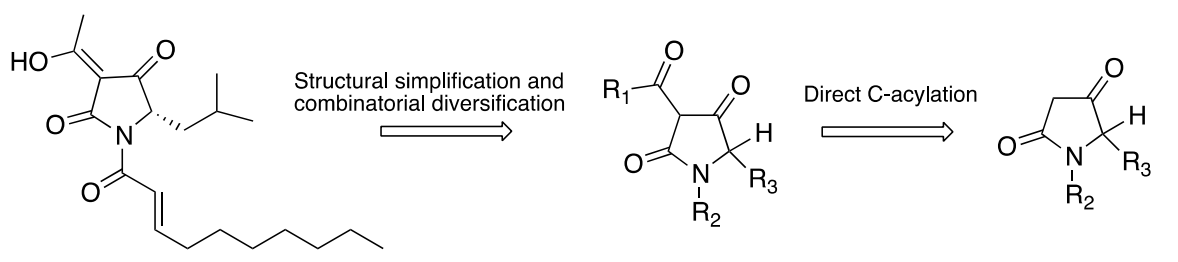

Reutericyclin

Figure 4 


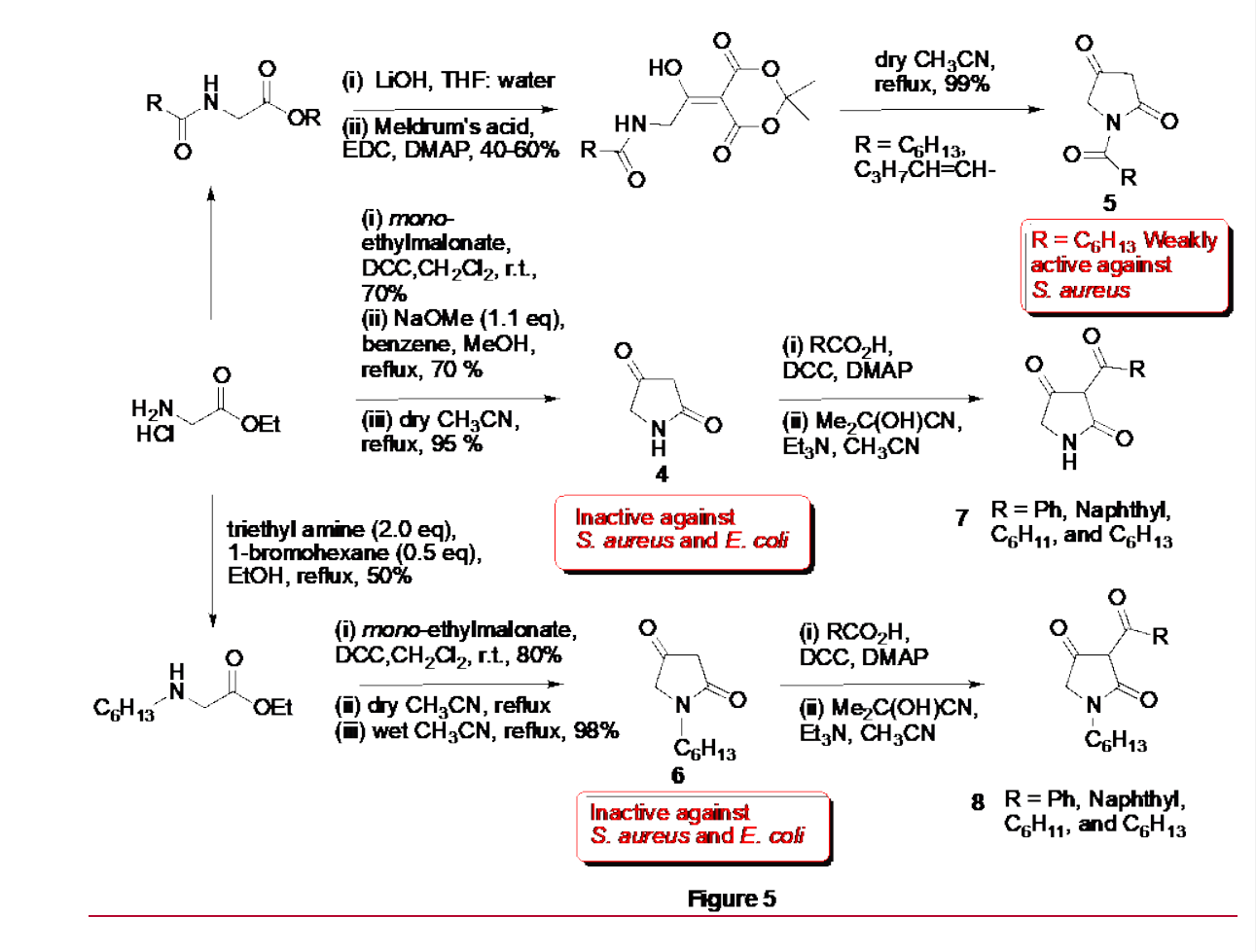




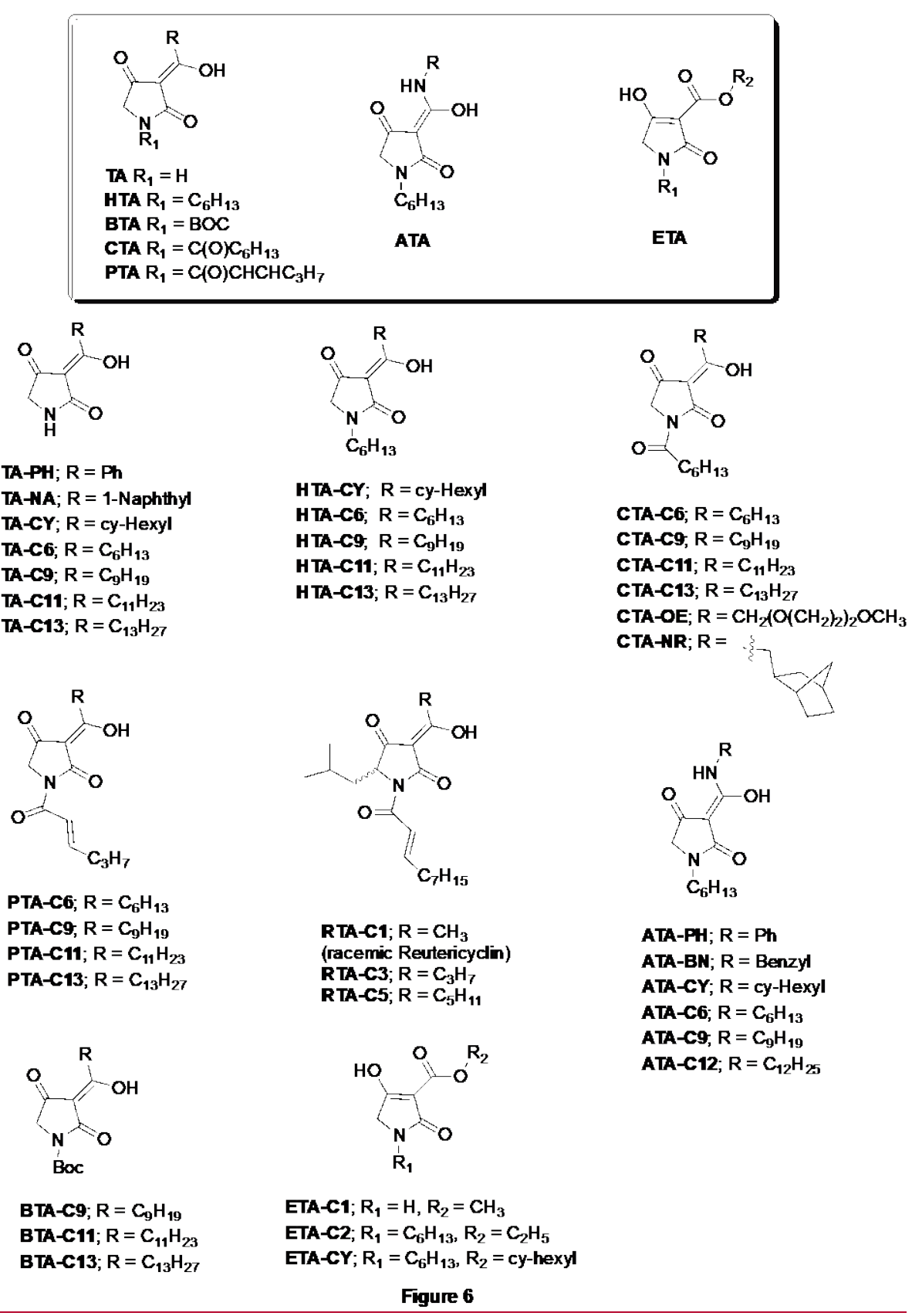




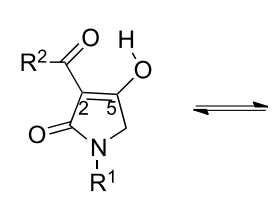

A

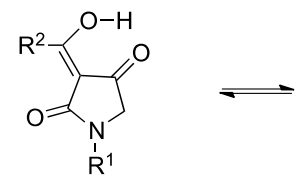

B<smiles>[R]C(O)=C1C(=O)CN([R1])C1=O</smiles>

c

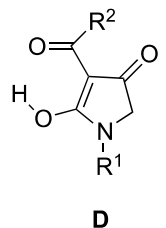

D

Figure 7

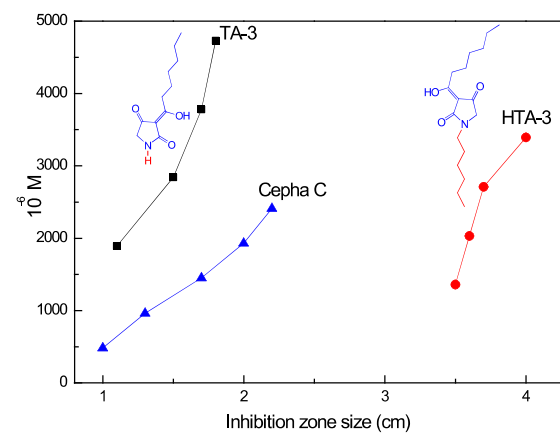

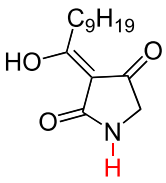

MIC: $(\mu \mathrm{g} / \mathrm{ml})$

S. aureus

6.25

Chem. Pharm. Bull. 1984, 32, 4197

Chem. Pharm. Bull. 1980, 28, 2494.

Table 1: Antibacterial activity of selected compounds from Figure 5.

\begin{tabular}{|c|c|c|c|c|}
\hline \multirow{2}{*}{ Entry } & \multirow{2}{*}{ Compounds } & \multicolumn{3}{|c|}{ Minimum inhibition concentration $(\mu \mathrm{g} / \mathrm{ml})^{\mathrm{a}}$} \\
\cline { 3 - 5 } & & $\frac{\text { Staphylococcus aureus }}{\underline{\text { D267 }}}$ & \multicolumn{2}{|c|}{$\underline{\text { Escherichia coli X580 }}$} \\
\cline { 3 - 5 } & & $\underline{\text { Neutral pH }}$ & $\underline{\mathrm{pH} 4.5 \text { buffer }}$ \\
\hline$\underline{1}$ & $\underline{\text { TA-PH }}$ & $\underline{3000}$ & $\underline{4000}$ & $\underline{800}$ \\
\hline$\underline{2}$ & $\underline{\text { TA-NA }}$ & $\underline{2000}$ & $\underline{2000}$ & $\underline{1000}$ \\
\hline$\underline{3}$ & $\underline{\text { TA-CY }}$ & $\underline{800}$ & $\underline{800}$ & $\underline{400}$ \\
\hline$\underline{4}$ & $\underline{\text { TA-C6 }}$ & $\underline{400}$ & $\underline{200}$ & $\underline{20}$ \\
\hline$\underline{5}$ & $\underline{\text { TA-OPH }}$ & $\underline{>4000}$ & $\underline{800}$ & $=$ \\
\hline
\end{tabular}




\begin{tabular}{|c|c|c|c|c|}
\hline$\underline{6}$ & $\underline{\text { TA-ONA }}$ & $\underline{>4000}$ & $\underline{400}$ & $=$ \\
\hline$\underline{7}$ & $\underline{\text { TA-OCY }}$ & $\underline{>4000}$ & $\underline{800}$ & $=$ \\
\hline$\underline{8}$ & $\underline{\text { TA-OC6 }}$ & $\underline{>4000}$ & $\underline{800}$ & $=$ \\
\hline$\underline{9}$ & $\underline{\text { Cephalosporin Cc }}$ & $\underline{200}$ & $\underline{2}$ & $=$ \\
\hline
\end{tabular}

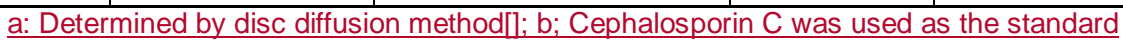




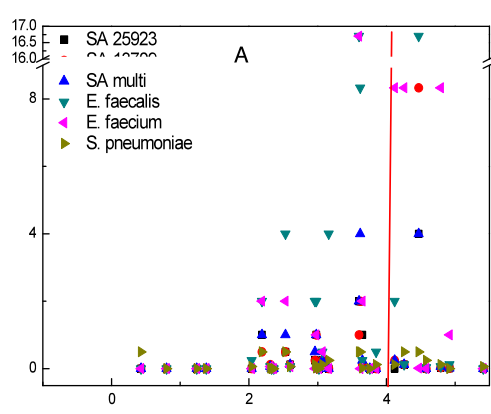

D

E

C

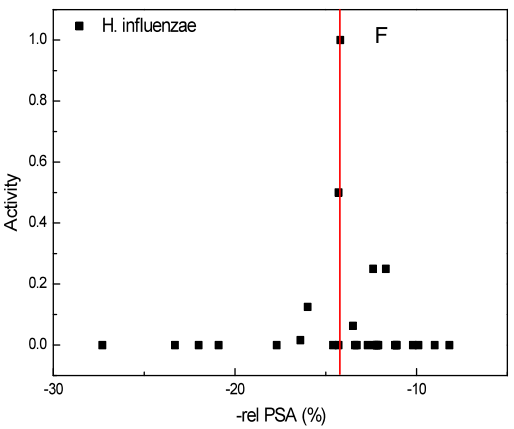

-rel PSA (\%)

Figure 9 
Table 2: Active compounds and their cheminformatic descriptors.

\begin{tabular}{|l|l|l|l|l|}
\hline$\underline{\text { Compounds }}$ & $\begin{array}{l}\underline{\mathrm{MIC}(\mu \mathrm{g} / \mathrm{ml},} \\
\underline{\text { S. aureus) }}\end{array}$ & $\underline{\underline{\text { ClogP }}}$ & $\underline{\mathrm{MSA}}$ & $\underline{\text { rel PSA }}$ \\
\hline$\underline{\text { Most active: CTA-C9, RTA-C3 \& RTA-C5 }}$ & $\underline{\underline{0.125-0.5}}$ & $\underline{3.6-4.47}$ & $\underline{631-693}$ & $\underline{11.2-12.3}$ \\
\hline$\underline{\text { Active: TA-C11, CTA-NR \& CTA-C6 }}$ & $\underline{0.5-2}$ & $\underline{2.19-2.98}$ & $\underline{483-545}$ & $\underline{14.2-14.3}$ \\
\hline
\end{tabular}

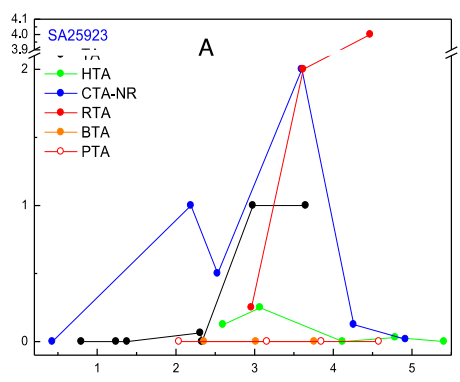

B

C

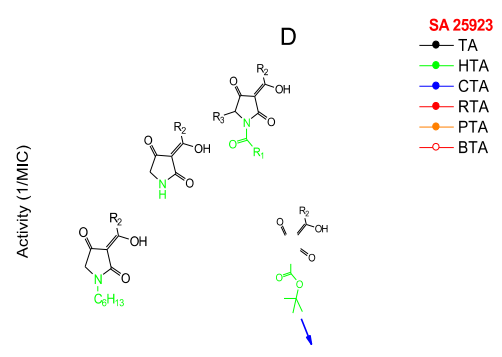




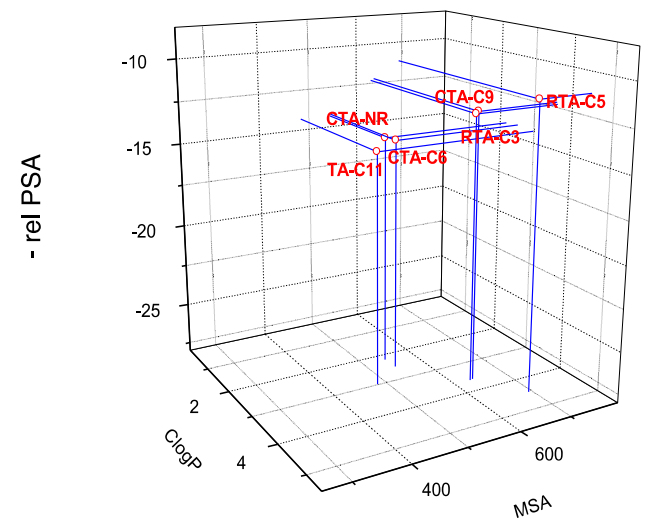

Figure 11 


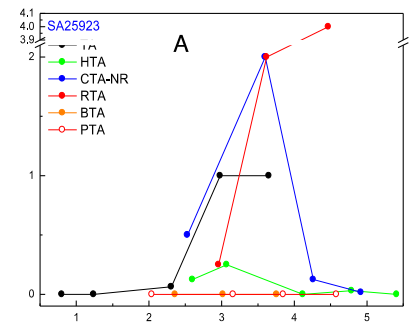

B

C

Figure 12

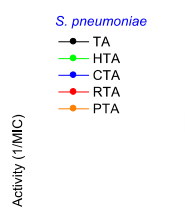

D

E

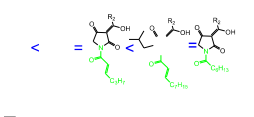

F

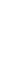

ClogP 

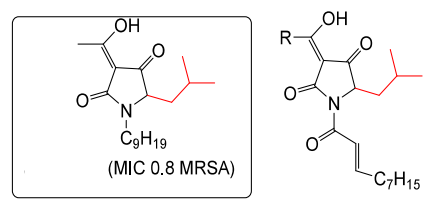

MIC 0.25 MRS

VII

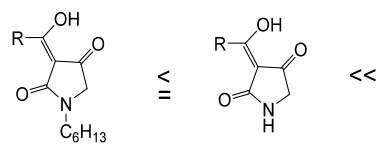

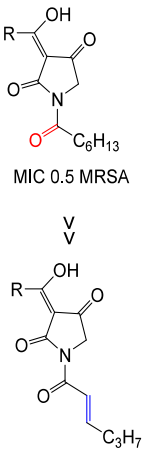

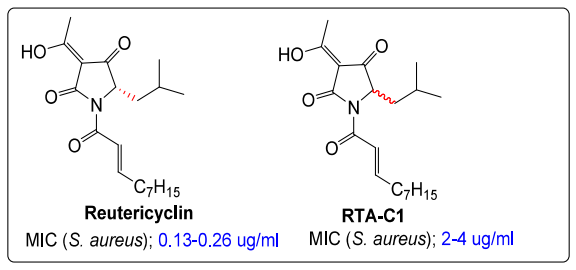

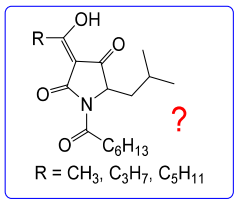

II
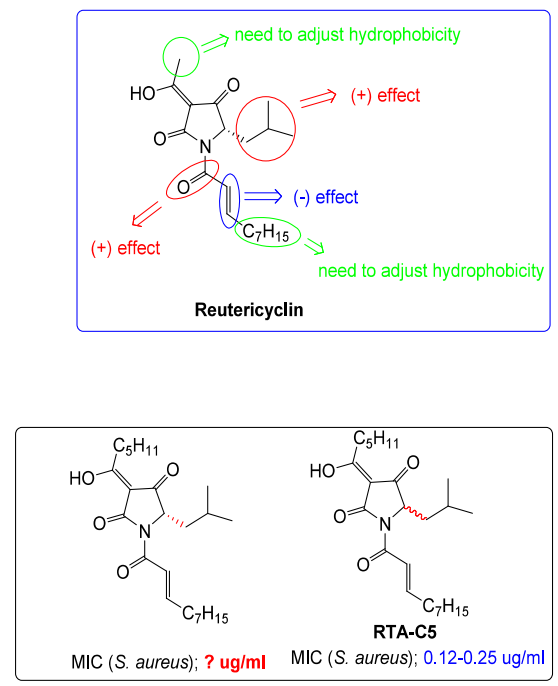

Figure 13 

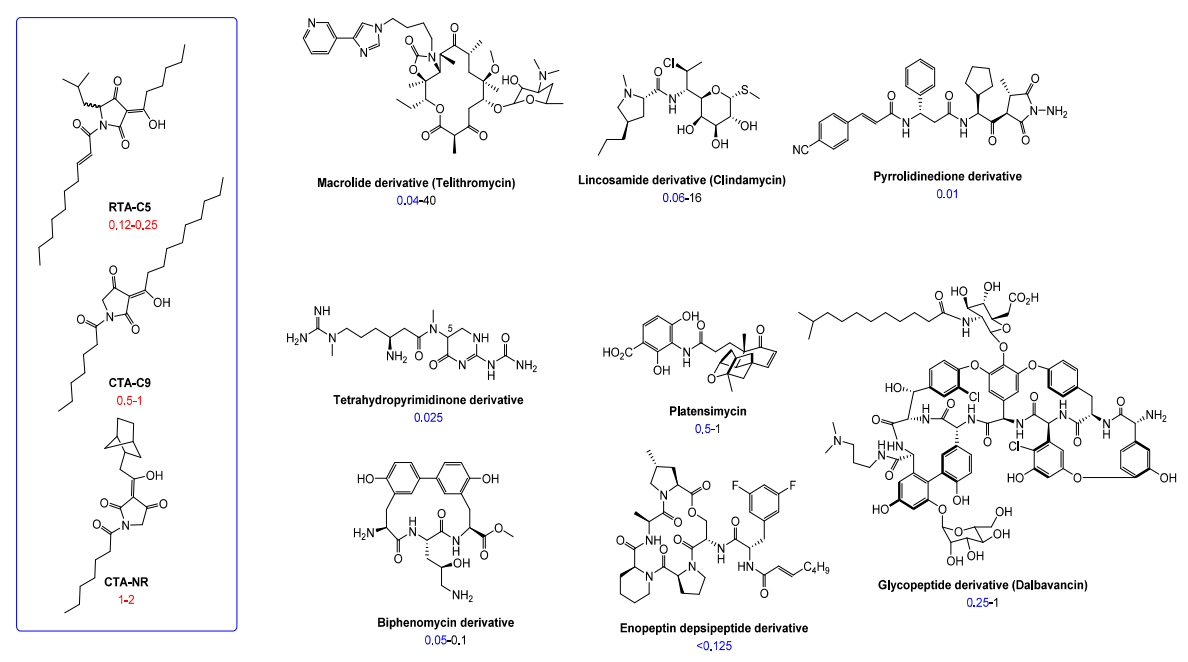

Figure 14

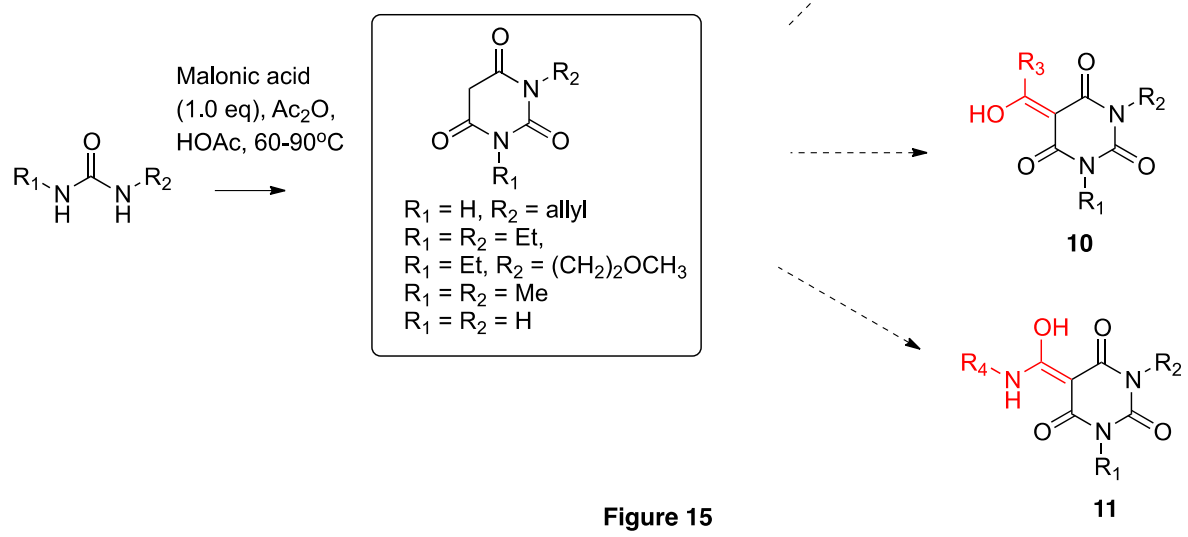




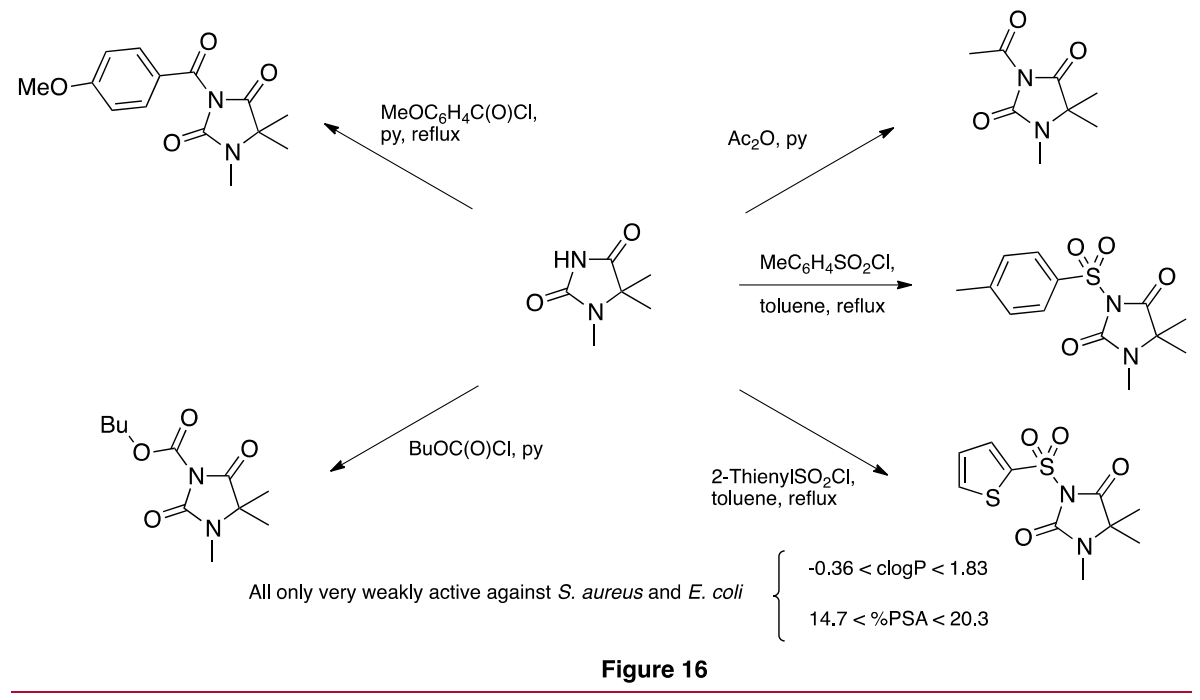

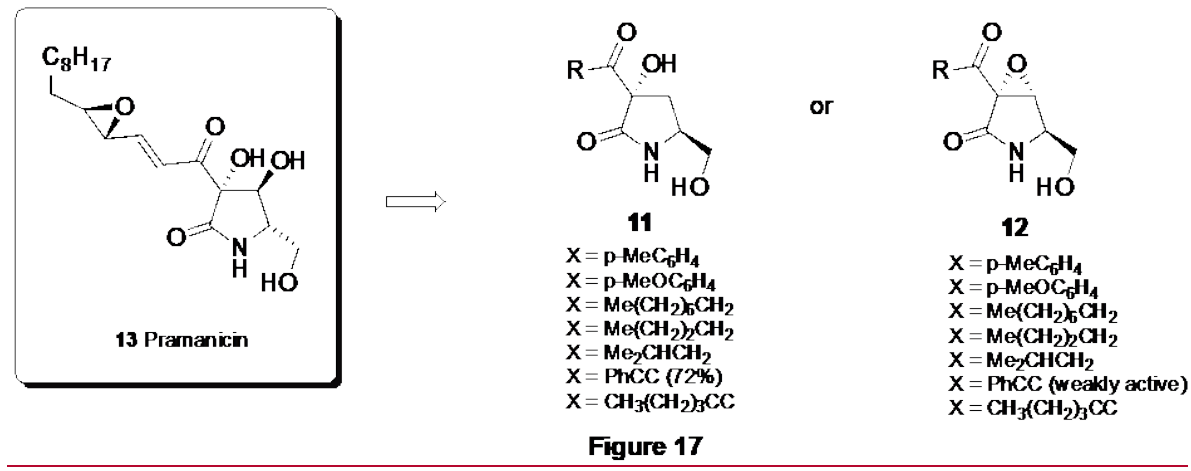

